\title{
Chinese validation and clinical application of the tinnitus functional index
}

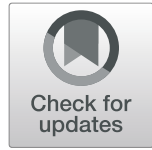

\author{
Xianren Wang ${ }^{1,2^{*}}$, Ruyan Zeng ${ }^{1,2}$, Huiwen Zhuang ${ }^{1,2}$, Qiyang Sun ${ }^{1,2}$, Zijun Yang ${ }^{1,2}$, Cangjian Sun ${ }^{1,2}$ and \\ Guanxia Xiong ${ }^{1,2^{*}}$
}

\begin{abstract}
Objective: The Tinnitus Functional Index (TFI) is a new diagnostic measure of the functional impact of tinnitus that is also a sensitive measure of treatment-related changes. However, the TFI has not been translated into Chinese and fully validated in China. The aim of the present study was to evaluate the validity of a Chinese version of the TFI as a diagnostic measure of tinnitus severity in a sample of Chinese patients and to verify the value of its clinical application in China.
\end{abstract}

Design: A sample of 206 patients whose primary complaint was tinnitus was used to analyze the reliability and validity of the TFI. In addition, patients were asked to fill out the Tinnitus Handicap Inventory (THI) and the Center for Epidemiologic Studies-Depression Scale (CES-D), the Beck Anxiety Inventory (BAI), and the Satisfaction With Life Scale (SWLS) to compare TFI with their association. The internal consistency of the TFI was assessed with Cronbach's alpha coefficient. The factor structure of the TFI was assessed by Exploratory Factor Analysis (EFA). The extracted factors were compared to those of the original TFI scale.

Results: The reliability of the Chinese version of the TFI (Cronbach's $a=.969)$ showed high internal consistency. The exploratory factor analysis (EFA) of the TFI showed that six factors with one main factor could be extracted instead of eight factors as described in the original version. Nevertheless, relations to the original eight subscales could be demonstrated. A high correlation between the TFI and the THI $(r=.865, p<0.01)$ and lower correlations between the TFI and the CES-D $(r=.334, p<0.01)$, BAI $(r=.559, p<0.01)$, and SWLS $(r=-0.324, p<0.01)$ confirmed the satisfactory convergent and discriminant validity of the TFI.

Conclusion: After translated and validated a Chinese version of the TFI and found that the TFI had high reliability and validity, which means both instruments are reliable instruments to assess the severity of tinnitus in clinical applications in China.

Keywords: China, Reliability and validity, Tinnitus, Index

\footnotetext{
*Correspondence: wangxianrend@126.com; xgx001@126.com

'Department of Otorhinolaryngology, The First Affiliated Hospital, Sun

Yat-Sen University, Guangzhou 510080, People's Republic of China

Full list of author information is available at the end of the article
}

(C) The Author(s). 2020 Open Access This article is licensed under a Creative Commons Attribution 4.0 International License, which permits use, sharing, adaptation, distribution and reproduction in any medium or format, as long as you give appropriate credit to the original author(s) and the source, provide a link to the Creative Commons licence, and indicate if changes were made. The images or other third party material in this article are included in the article's Creative Commons licence, unless indicated otherwise in a credit line to the material. If material is not included in the article's Creative Commons licence and your intended use is not permitted by statutory regulation or exceeds the permitted use, you will need to obtain permission directly from the copyright holder. To view a copy of this licence, visit http://creativecommons.org/licenses/by/4.0/ The Creative Commons Public Domain Dedication waiver (http://creativecommons.org/publicdomain/zero/1.0/) applies to the data made available in this article, unless otherwise stated in a credit line to the data. 


\section{Introduction}

Tinnitus is a subjective sensation in the ear without a corresponding external sound source or external stimulus [1]. Epidemiology study estimate that $10-15 \%$ of the adult population experiences chronic tinnitus [2]. However, there currently is no large-scale epidemiological survey of tinnitus in China. Some researchers have conservatively estimated that $10.4 \%$ of people in south China have experienced tinnitus, of which 5\% have sought medical treatment, and $2 \%$ have been seriously affected by it with respect to life, sleep, work, and social activities [3]. In addition, $0.5 \%$ of patients with tinnitus in this population have a disability because of its severity [3]. The mental and psychological problems caused by tinnitus are becoming increasingly prominent, and more attention needs to be paid to the association between tinnitus severity and anxiety and depression [4].

As tinnitus is a subjective feeling, there is no objective method to measure its severity or assess the effects of treatment for tinnitus [5]. Therefore, it has been necessary to use scales or other types of questionnaires to evaluate the severity of tinnitus and patients' responses to treatment quantitatively.

Several questionnaires have been developed over the years to evaluate the severity of tinnitus, including the Tinnitus Handicap Inventory (THI) [6], the Tinnitus Handicap Questionnaire (THQ) [7], the Tinnitus Activity Questionnaire (TAQ) [8], the Tinnitus Reaction Questionnaire (TRQ) [9], the Tinnitus Questionnaire (TQ) [10], and the Tinnitus Functional Index (TFI) [11]. Most of Chinese language tinnitus questionnaires that are in use have not been translated or validated according to accepted scientific methodology [12]. In China, the THI scale is widely used in China after being translated and verified by Qiulan Shi [13]. It is a scale commonly used in China to assess the severity of tinnitus. Therefore, in order to verify the assessment of tinnitus severity on the TFI scale, it can be verified with the THI scale. Those that have been statistically validated, such as the THI, TAQ, and THQ [14], were not developed specifically to detect changes in tinnitus-related treatment. The TFI, on the other hand, was specifically developed to be both a diagnostic measure of the functional impact of tinnitus and to be a sensitive measure of treatment-related changes [11]. It has been translated to more than 10 languages and has demonstrated convergent validity [15]. TFI consists of eight sub-scales, which are used to quantitatively evaluate the degree of patients' tinnitus effects in the dimensions of Intrusive, Sense of control, Cognitive, Sleep, Auditory, Relaxation, Quality of life, and Emotional. Thus the evaluation scale in view of the wider range, and excellent psychometric properties $[11,16,17]$. Therefore, the primary goal of this study was to produce a cross-culturally valid Chinese-language version of the TFI and to report its psychometric properties, in order to provide clinicians and researchers who work within the tinnitus field in China with an alternative instrument to those already in use.

\section{Materials and methods}

Research participants

A total of 206 outpatients in the First Affiliated Hospital of Sun Yat-sen University were recruited for the study, 175 participants were included from May to September 2018 and the others were recruited from March to May 2020. The inclusion criteria were patients who had tinnitus for longer than 6 months, normal intelligence, no communication barriers, the ability to understand the content of the scales, and the ability to answer the questions. The exclusion criteria were objective tinnitus or a history of suppurative otitis media. The study participants were 106 males and 100 females between 18 and 65 years of age. Participation was voluntary, and all the participants gave oral consent before completing the scales; the data were stored and analyzed anonymously.

\section{Translation and cross-cultural adaptation}

The original version of the TFI was independently translated into Chinese by the two authors, both of whom are native Chinese speakers with advanced skills in the English language and expertise in tinnitus. A third forward translation was made by a bilingual expert in healthcare questionnaires with no prior knowledge of the TFI. The three translations were then compared and synthesized into the first prototype of the TFI-CN. Then, two backtranslations were performed by a bilingual medical scientist and a professional translator. The back-translations were subsequently compared to the original TFI by an expert panel consisting of the authors, the translators, and three colleagues from tinnitus clinics. All discussions, comments, and the final revision were documented [18].

\section{Research instruments \\ Tinnitus handicap inventory (THI)}

The THI consists of 25 questions that are answered "Yes," "Sometimes," and "None." And the scale is divided into three subscales: functional, catastrophic, and emotional. The scale's total possible score is 100 points: 4 points for "Yes," 2 points for "Sometimes," and 0 points for "None." Newman et al. divided tinnitus disability into four levels. The first level $=0$ to 16 points (no disability); the second level = 18 to 36 points (mild disability); the third level $=38$ to 56 points (moderate disability); and the fourth level $=58$ to 100 points (severe disability).

\section{Tinnitus functional index (TFI)}

The TFI consists of 25 items that are divided into eight sub-scales of 3-4 items that measure the severity of 
different problems related to tinnitus. The scale is divided into 8 sub-scales (Intrusive, Sense of control, Cognitive, Sleep, Auditory, Relaxation, Quality of life, and Emotional) to deal with different areas of tinnitus severity. Each item is rated on a 0 to 10 scale $(0=$ never or not at all; $10=$ almost always or extremely), with the raw scores on each subscale multiplied by 10 to yield subscale scores of 0 to 100 . The total score is the average of the eight sub-scale scores.

\section{Center for Epidemiologic Studies-Depression Scale (CES-D)}

The CES-D, which was developed by Radloff at the National Institute of Mental Health in 1977, can be used as a clinical examination to assess the severity of depressive symptoms [15, 16]. The scale consists of 20 items, with each item measuring a symptom that respondents may have experienced during the past week. The response options are: "less than one day" ("no or not"); "1 to 2 days" ("rare"); "3 to 4 days" ("often"); and "5 to 7 days" ("almost always"). The main CES-D measure is its total score. A total score $\leq 15$ indicates no depressive symptoms, 16 to 19 points indicates the respondent may have depressive symptoms, and $\geq 20$ points indicates the respondent must have depressive symptoms.

\section{Satisfaction with life scale (SWLS)}

The SWLS consists of 5 statements that are scored from 1 (strongly disagree) to 7 (strongly agree), and summed to form a total score. Higher scores indicate greater life satisfaction [19].

\section{Beck anxiety inventory (BAI)}

The BAI is a self-report measure of anxiety that consists of 21 symptoms of anxiety. Respondents are asked to rate the degree to which they have been bothered or annoyed by each symptom during the past month on a 4-point scale: "not at all" = 1; "mildly, no major annoyance" = 2; "moderately, feels uncomfortable but still tolerable" $=3$; and "severe, can barely endure" $=4$ [20].

\section{Statistical analysis \\ Processing of missing data}

All the participants were given oral instructions about how to complete the scales and were asked not to omit any items or mark more than one answer for each item. According to the instructions of the authors of the original scales for computing the subscale and total scores in cases where the scales were incomplete. If two or more questions are not answered, the scale was considered invalid and rejected. The missing data were estimated using the multiple imputation [21] .

\section{Pearson's correlations}

The convergent validity of the TFI was compared with THI, and the discriminant validity of the TFI with the CES-D, SWLS, and BAI were analyzed using Pearson's correlation coefficients. An $r>.8$ indicates a strong correlation between two variables; an $r<.3$ indicates a weak correlation between two variables.

\section{Reliability analysis}

The reliability of the Chinese versions of the TFI and THI were measured by Cronbach's $\alpha$ coefficient for internal consistency; the internal consistency of the total scores of the TFI and THI scales and their individual items were tested. Cronbach's $\alpha>.7$ indicates the agreement between the items is good; Cronbach's $\alpha<.5$ indicates items need to be eliminated.

\section{Validity analysis}

Bartlett's Test of Sphericity and the Kaiser-Meyer-Olkin (KMO) test were conducted to evaluate the appropriateness of performing factor analysis. The factor analysis tested the eigenvalues of the 25 items on the scale, identified the items with eigenvalues greater than 1 , or the Jolliffe's criterion has a suggested cut-off for eigenvalues greater than 0.7 [22], and calculated the cumulative variance to extract the common factors in the scale.. The significance level was set at $p \leq 0.05$ (two sided), unless otherwise specified. The factor matrix was rotated to determine the items corresponding to each dimension, and the items with the highest commonality on the scale were evaluated. Factor analysis was carried out using the oblique rotation [16, 23, 24]. The McDonald's omega, including hierarchical subscale and omega total, are also used to further evaluate the dimensionality of the scale [25]. The above analyses were computed with the latest R (4.0.2) software (The $\mathrm{R}$ Foundation for Statistical Computing, Vienna, Austria) with psych package and IBM SPSS version 22 (International Business Machines Corporation, Armonk, NY, USA).

\begin{tabular}{lll}
\multicolumn{2}{l}{ Table $\mathbf{1}$ The score of and TFI $(n=206)$} & \\
\hline Scale & Average & Standard deviation \\
\hline TFI & 33.14 & 22.75 \\
Intrusive & 48.46 & 26.82 \\
Sense of control & 38.66 & 23.91 \\
Cognitive & 29.22 & 26.49 \\
Sleep & 34.14 & 31.94 \\
Auditory & 23.82 & 27.16 \\
Relaxation & 36.68 & 30.17 \\
Quality of life & 22.44 & 25.69 \\
Emotional & 35.29 & 28.61 \\
\hline
\end{tabular}


Table 2 Tinnitus severity rating of TFI $(n=206)$

\begin{tabular}{llll}
\hline Scale & Severity & Patient $\mathrm{n}$ & Percent $\%$ \\
\hline TFI & Not a problem & 68 & 33 \\
& A small problem & 44 & 21 \\
& A moderate problem & 57 & 28 \\
& A big problem & 28 & 14 \\
& A very big problem & 9 & 4 \\
\hline
\end{tabular}

\section{Results}

\section{Study participants}

A total of 206 outpatients with tinnitus were included in this study. The sample consisted of 106 males and 100 females between the ages 18 and 65 years-old; mean = 38.1 ( $\pm 12.4 \mathrm{SD})$ years-old. The mean duration of tinnitus was 10.6 months $( \pm 12.5 \mathrm{SD}$, range $=6-720$ months). All the participants received and completed the Chinese version of the THI and TFI, for a response rate of $100 \%$, as shown in Tables 1 and 2; 161 of the participants also completed the CES-D, BAI, and SWLS.

\section{Correlation and discriminant validity between the THI, TFI and other scales}

There was a strong positive correlation between the THI and TFI: $r=.865, p<0.01$. In addition to the negative correlation between SWLS and TFI scales, the other two psychological scales were positively correlated with TFI scales, and had a moderate correlation, all $p<0.01$, as shown in Table 3.

\section{Reliability of the Chinese versions of the TFI}

Cronbach's $\alpha$ (0.969), omega hierarchical (0.87) and omega total (0.99) for the Chinese TFI, which indicates the internal consistency of all the items in the scale was good (see Table 4). The correlations between the items and the total score (item-total correlations) ranged from .573 to .837 (detail see Table 5).

\section{Validity of the Chinese TFI using exploratory factor analysis}

The Kaiser-Meyer-Olkin (KMO) Measure of Sampling Adequacy and Bartlett's Test of Sphericity were assessed to assure that the data were eligible for exploratory factor analysis. The Bartlett's test of Sphericity was significant $(<0.001)$, indicating that the items of the TFI were correlated. The KMO value was 0.936 , which means the

Table 3 Correlations between the TFI and other measures used in the adaptation procedure

\begin{tabular}{llll}
\hline & CES-D $^{c}$ & BAl $^{c}$ & SWLS $^{c}$ \\
\hline TFI $^{\mathrm{b}}$ & $0.334^{\mathrm{a}}$ & $0.559^{\mathrm{a}}$ & $-0.324^{\mathrm{a}}$
\end{tabular}

${ }^{a} P<0.01$; TFI Tinnitus Functional Index, CES-D Center for Epidemiological Studies Depression, SWLS Satisfaction With Life Scale, BAI Beck Anxiety Inventory. ${ }^{\text {b }}: n=206 ;{ }^{c}: n=161$
Table 4 Cronbach's a analysis of each subscale of TFI $(n=206)$

\begin{tabular}{ll}
\hline Scale & Cronbach's a \\
\hline TFI & 0.968 \\
Intrusive & 0.849 \\
Sense of control & 0.836 \\
Cognitive & 0.937 \\
Sleep & 0.945 \\
Auditory & 0.942 \\
Relaxation & 0.939 \\
Quality of life & 0.919 \\
Emotional & 0.919 \\
\hline
\end{tabular}

TFI Tinnitus Functional Index

Table 5 Corrected item total correlation for all items of the TFI $(n=206)$

\begin{tabular}{ll}
\hline Item & Corrected item-total correlation \\
\hline I1 & 0.573 \\
I2 & 0.729 \\
I3 & 0.695 \\
SC1 & 0.779 \\
SC2 & 0.689 \\
SC3 & 0.721 \\
C1 & 0.837 \\
C2 & 0.758 \\
C3 & 0.756 \\
SL1 & 0.673 \\
SL2 & 0.728 \\
SL3 & 0.670 \\
A1 & 0.675 \\
A2 & 0.687 \\
A3 & 0.719 \\
R1 & 0.742 \\
R2 & 0.778 \\
R3 & 0.748 \\
Q1 & 0.792 \\
Q2 & 0.806 \\
Q3 & 0.770 \\
Q4 & 0.768 \\
E1 & 0.785 \\
E2 Quality of life, $E$ Emotional & 0.812 \\
\hline & 0.710 \\
\hline
\end{tabular}


partial correlations were weak, indicating that the scale was suitable for factor analysis. Principal component analysis with Promax rotation was used to analyze the scale and the resulting communalities ranged from 0.64 to 0.94 . The number of components of the TFI was defined based on the eigenvalues. The scree plot showed a very sharp decline after the first factor (Fig. 1). and virtually drawn horizontal and vertical lines starting from each end of the curve indicated that only one factor point was above the point of inflexion. However, by applying Jolliffe's criterion, a six-factor structure could be retained (Table 6) and these six factors explained 83.35\% of the total variance. With reference to the original TFI's eight factors, a principal component analysis with promax rotation and eight fixed factors was performed (Table 7). Although the eigenvalues of the last factors were smaller than 0.7 , there were correlations between the items and their factors. Only Factor 8, standing for quality of life, was represented by only one item, Q4. Items Q1 and Q3 were also expected to correlate with this factor but did not. Rather, both Items correlated strongly with Factor 1 (intrusiveness). Q2 loaded on the second factor, standing for relaxation. as shown in Table 7 . These results indicated that the instrument was structurally efficient.

\section{Factorial validity}

To reconfirm the EFA results, the McDonald omega hierarchical subscale analyses were further evaluated. The McDonald omega results indicated that the TFI-CN possesses an eight-factor structure with relatively large omegaHS values $[25]\left(\omega_{\text {hs.I }}=0.57 ; \omega_{\text {hs.SC }}=0.64 ; \omega_{\text {hs.C }}=\right.$ $0.68 ; \omega_{\text {hs.SL }}=0.48 ; \omega_{\text {hs.A }}=0.47 ; \omega_{\text {hs. }}=0.60 ; \omega_{\text {hs } . \mathrm{Q}}=0.75 ;$ $\omega_{\mathrm{hs} . \mathrm{E}}=0.67$; I, Intrusive; SC, Sense of control; C, Cognitive; SL, Sleep; A, Auditory; R, Relaxation; Q, Quality of life; E, Emotional), show as Fig. 2. The result indicated that that the 25-item TFI with an eight-factor structure possesses good factorial validity.

\section{Discussion}

The TFI have been translated into many different languages since they were originally published and all the versions have demonstrated good reliability and validity $[15,17,26,27]$. However, the TFI has not been translated into Chinese and validated in China. The present study found the Chinese versions of TFI had excellent internal consistency (Cronbach's $\alpha$ of .969), similar to their Polish versions (Cronbach's $\alpha$ of .960), and the original versions (Cronbach's $\alpha$ of .97) [11, 24]. The TFICN's convergent validity with the THI was high $(r=$ $.865)$ and comparable to the English version $(r=.75)$. The positive correlations of the TFI-CN with the CES-D $(r=.334, p<0.01)$ and BAI $(r=0.559, p<0.01)$ were stronger than the negative correlation between the TFI$\mathrm{CN}$ and the SWLS $(r=-.324, p<0.01)$, all of which we interpret as satisfactory discriminant validity.

The Polish version of the TFI scale has an overall Cronbach's $\alpha$ of .960, which is comparable to that of the Chinese version (Cronbach's $\alpha=.969$ ), but Cronbach's $\alpha$

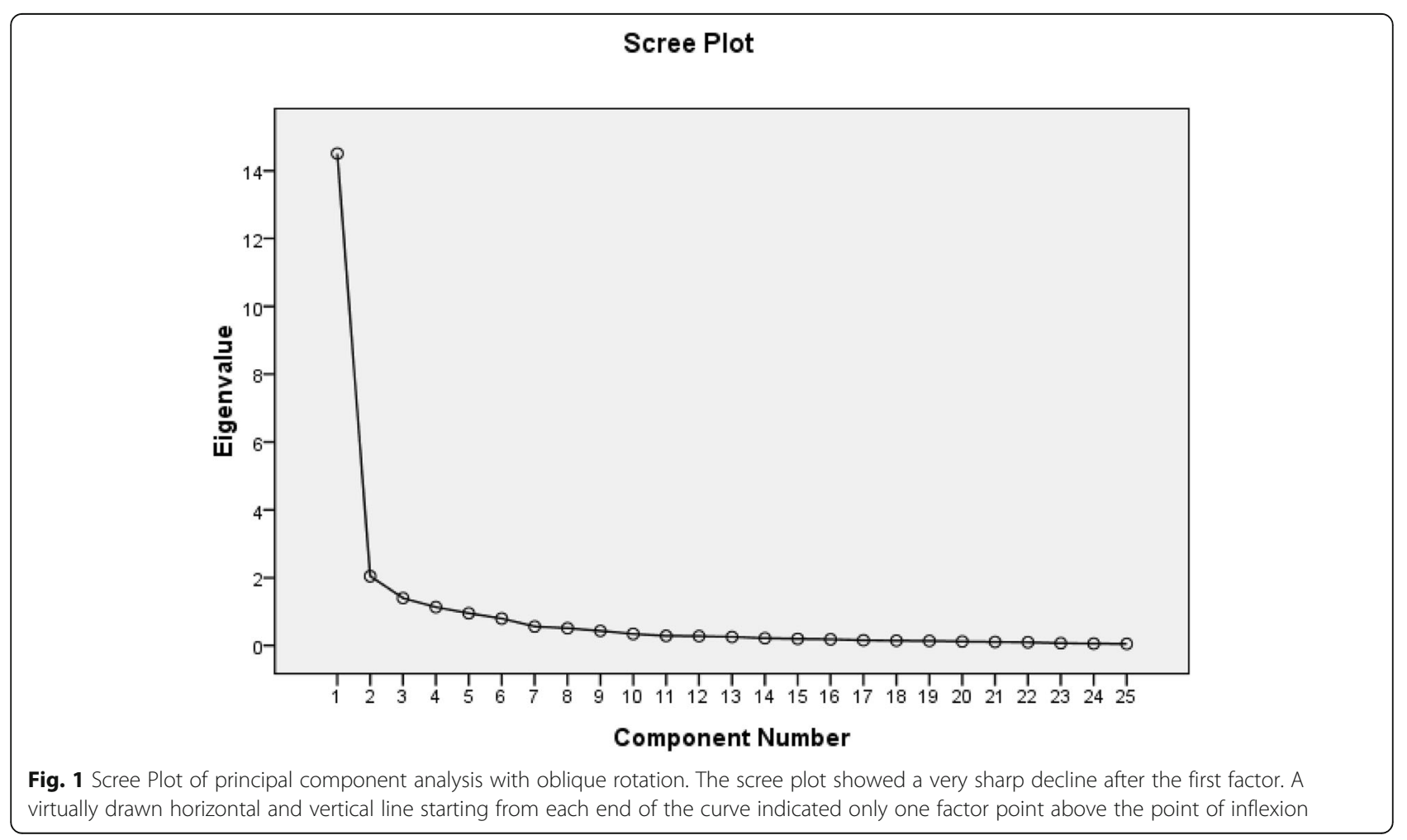


Table 6 Principal component analysis with Promax rotation

\begin{tabular}{|c|c|c|c|c|c|c|}
\hline \multirow[t]{2}{*}{ Item } & \multicolumn{6}{|c|}{ Factor } \\
\hline & 1 & 2 & 3 & 4 & 5 & 6 \\
\hline$\overline{A 3}$ & 0.860 & & & & & \\
\hline$A 2$ & 0.854 & & & & & \\
\hline $\mathrm{A} 1$ & 0.770 & & & & & \\
\hline Q1 & 0.680 & 0.422 & & & & \\
\hline Q3 & 0.622 & 0.396 & & & & \\
\hline Q4 & 0.549 & & & & & \\
\hline R3 & & 0.771 & & & & \\
\hline $\mathrm{R} 1$ & & 0.757 & & & & \\
\hline R2 & & 0.750 & & & & \\
\hline Q2 & 0.470 & 0.596 & & & & \\
\hline SL2 & & & 0.857 & & & \\
\hline SL1 & & & 0.856 & & & \\
\hline SL3 & & & 0.764 & & & \\
\hline 13 & & & & 0.722 & & \\
\hline 11 & & & & 0.722 & & \\
\hline 12 & & & & 0.597 & & \\
\hline SC2 & & & 0.355 & 0.561 & & \\
\hline $\mathrm{SC} 3$ & & & & 0.543 & & \\
\hline $\mathrm{C} 2$ & & & & & 0.746 & \\
\hline$C 3$ & 0.367 & & & & 0.711 & \\
\hline $\mathrm{C} 1$ & & & 0.352 & & 0.623 & \\
\hline $\mathrm{SC} 1$ & & & 0.383 & & 0.460 & \\
\hline E1 & & 0.355 & & & & 0.698 \\
\hline E2 & & & & & & 0.680 \\
\hline E3 & & & & & & 0.597 \\
\hline
\end{tabular}

for the Chinese version is slightly higher. The item-total correlations of the Chinese TFI are .562-.848, whereas the item-total correlation of the Polish TFI are .83-.95. As the item-total correlations of these two versions of the TFI are .30 or more, this indicates the Chinese version of the TFI has good internal reliability.

This study used factor analysis to test the structural validity of the scales. Similar as the scree plot of the German version, TFI-CN also indicated only one dominant factor with a high eigenvalue of 14.51 and all following eigenvalues $\leq 2.1$. However, using the Jolliffe's criterion (eigenvalues $>0.7$ ), six factors could be extracted. Other studies have also failed to reproduce the original eight factor structure. For example, in the validation of the Polish TFI [24] and German TFI [23], 5 factors were identified; and in the Swedish TFI [28] validation, 6 factors were extracted; in the Dutch version TFI 7 factors were found [16].

Of our extracted six factors when using the Jolliffe's criterion (eigenvalues >0.7), Factor 1 included two
Table 7 Rotated factor loading matrices of the predefinedfactor models with fixed eight factors

\begin{tabular}{|c|c|c|c|c|c|c|c|c|}
\hline Item & Factor & & & & & & & \\
\hline & 1 & 2 & 3 & 4 & 5 & 6 & 7 & 8 \\
\hline$\overline{\mathrm{A} 2}$ & 1.041 & & & & & & & \\
\hline A3 & 1.017 & & & & & & & \\
\hline $\mathrm{A} 1$ & 0.962 & & & & & & & \\
\hline Q1 & 0.515 & & & & & & & \\
\hline Q3 & 0.375 & & & & & & & \\
\hline $\mathrm{R} 1$ & & 1.038 & & & & & & \\
\hline R3 & & 0.988 & & & & & & \\
\hline R2 & & 0.961 & & & & & & \\
\hline Q2 & & 0.489 & & & & & & \\
\hline SL3 & & & 0.985 & & & & & \\
\hline SL1 & & & 0.981 & & & & & \\
\hline SL2 & & & 0.911 & & & & & \\
\hline $\mathrm{C} 2$ & & & & 1.050 & & & & \\
\hline $\mathrm{C} 3$ & & & & 1.047 & & & & \\
\hline $\mathrm{C} 1$ & & & & 0.737 & & & & \\
\hline E1 & & & & & 0.915 & & & \\
\hline E3 & & & & & 0.888 & & & 0.470 \\
\hline E2 & & & & & 0.833 & & & \\
\hline 11 & & & & & & 1.084 & & \\
\hline 13 & & & & & & 0.861 & & \\
\hline SC2 & & & & & & & 0.677 & \\
\hline SC3 & & & & 0.352 & & & 0.544 & \\
\hline 12 & & & & & & & 0.443 & \\
\hline Q4 & 0.368 & & & & & & & 0.573 \\
\hline SC1 & & & & 0.362 & & & & 0.569 \\
\hline
\end{tabular}

subscales of the original TFI consisting of Auditory and Quality of life. The validation of the Dutch TFI and German TFI, quality of life was loaded in one subscale with cognitive interference. This finding maybe can be explained Chinese of mandarin more focus on the hearing loss, hearing loss more effect on the quality of life. Factor 4 included two other subscales of the original TFI consisting of Intrusive and Sense of control. The version of German TFI has also the same result.

To verify the eight subscales of the original TFI, a factor analysis with eight fixed factors was performed. Despite the fact that the eigenvalues of the last two factors were smaller than 0.7, correlations between the items and their corresponding factors could be demonstrated. Only the last factor, Factor 8 (quality of life), was represented by only one item, Q4. The other items, Q1 and Q3, which were expected to correlate with this factor were strongly corelated with Factor 1 (auditory). 


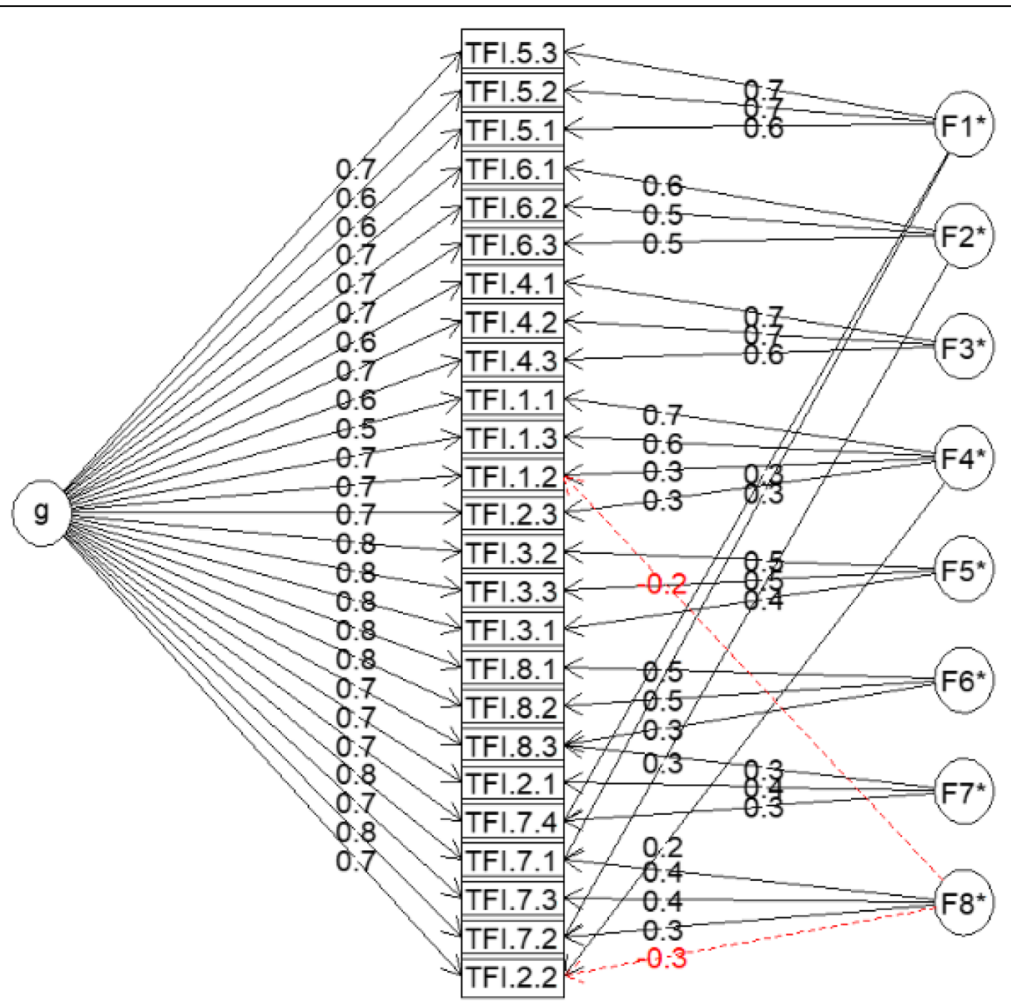

Fig. 2 Estimated model for the 25-item TFI Scale with eight-factor structure. TFI.1 represent Intrusive; TFI.2represent Sense of control; TFI.3 represent Cognitive; TFI.4 represent Sleep; TFI.5 represent Auditory; TFI.6 represent Relaxation; TFI.7 represent Quality of life; TFI.8 represent Emotional

Summary, the results of this study are similar to those from other studies validating the TFI in different languages. To our knowledge, the current study is the first to validate a Mandarin version for Chinese of the TFI. The factor analysis used to test the structural validity of the Chinese version of the TFI found it contained six factors EFA explored Chinese version TFI with fixed 8 factor analysis has 8 factors and consistent with the origin version, except the last factor 8 which only one item was loaded in. However, there are lots of limitation need to be further clarify, such as the sample size. Although the sample size determination for psychometric validation studies is always lack of clear scientifically sound recommendations on this topic [29]. In the present we recruited 206 tinnitus patients. And in the verification of the THI scale, this article compares the sample size of 199 cases of references in the Chinese version of THI [13], and the statistical results of the THI scale also agree with the results. Both THI and TFI have the same 25-items, the sample size should be also enough for the TFI, however the small size sample also could cause bias and may limited the validity and reliability of our findings. So, the bigger sample size should be recruited and be used to further validation. More and more literatures evaluate and validate new scales with both EFA and CFA
[30, 31]. In the present we just used EFA to confirm the reliability and validity of the TFI-CN, we will collect more independent data to replicate and evaluate the construct validity of the scales with CFA. But we run omega hierarchical subscale to reconfirm the EFA validity, the results suggest TFI-CN has good reliability and validity. Finally, our study still demonstrated that the Mandarin version of the TFI for Chinese is a suitable instrument for measuring the impact of tinnitus. The reliability and validity of this version are very good and comparable with the original version of TFI. It can be used to assess tinnitus in clinical.

\section{Conclusion}

The results suggest the Chinese versions of the TFI scales have high reliability and validity and can be used to assess the severity of clinical tinnitus and treatmentrelated changes in tinnitus. The TFI-CN has excellent internal reliability and satisfactory convergent and discriminant validity. Finally, one thing to emphasize is that having Chinese versions of tinnitus scales will make it possible for Chinese researchers to become active within international scientific networks. In light of the complex nature of tinnitus, collaboration between different research communities will be of great importance. By 
using the TFI-CN, Chinese scientists will not only be able to compare and report the results of their studies on tinnitus, but also become valued contributors on international scientific platforms.

\section{Abbreviations}

TFI: Tinnitus Functional Index; THI: Tinnitus Handicap Inventory; CESD: Center for Epidemiologic Studies-Depression Scale; BAl: Beck Anxiety Inventory; SWLS: Satisfaction with Life Scale; EFA: Exploratory factor analysis; THQ: Tinnitus Handicap Questionnaire; TAQ: Tinnitus Activity Questionnaire; TRQ: Tinnitus Reaction Questionnaire; TQ: Tinnitus Questionnaire; TFICN: Tinnitus Functional Index-China; THI-CN: Tinnitus Handicap InventoryChina; KMO: Kaiser-Meyer-Olkin

\section{Acknowledgements}

We acknowledge the Sun Yat-sen University for initiating a translation of the Tinnitus Functional Index and would like to thank the Sun Yat-sen University for providing us the license of this version.

\section{Authors' contributions}

XW collected data and monitored data collection for the whole trial, wrote the statistical analysis plan, cleaned and analyzed the data, contributed to the interpretation of data, drafted and revised the paper. RZ monitored data collection for the whole trial, wrote the statistical analysis plan, cleaned and analyzed the data, contributed to the interpretation of data and revised the drafted paper. $\mathrm{HZ}$ contributed to the interpretation of data and revised the drafted paper. QS translated the TFI scale, and revised the drafted paper. ZY collected data for the whole trial and revised the drafted paper. GX contributed to the interpretation of data and revised the drafted paper. QS translated the TFI scale, and revised the drafted paper. All authors read and approved the final manuscript.

\section{Funding}

This research was supported by grants from the National Natural Science Fund of China (81200748), the Natural Science Fund of Guangdong Province (2018A030313112), and the Science Plan Fund of Guangzhou (201803010033).

\section{Availability of data and materials}

Please contact author for data requests.

\section{Ethics approval and consent to participate}

The ethics committee of the Clinical Research and Experimental Animal of the First Affiliated Hospital of Sun Yat-sen University approved this study and all participants gave their written consent. The authors assert that all procedures contributing to this work comply with the ethical standards of the relevant national and institutional committees on human experimentation and with the Helsinki Declaration of 1975, as revised in 2008

\section{Consent for publication}

Not applicable.

\section{Competing interests}

The authors declare that they have no competing interests.

\section{Author details}

'Department of Otorhinolaryngology, The First Affiliated Hospital, Sun Yat-Sen University, Guangzhou 510080, People's Republic of China. ${ }^{2}$ Institute of Otorhinolaryngology, Sun Yat-Sen University, Guangzhou 510080, People's Republic of China.

Received: 18 May 2019 Accepted: 27 July 2020

Published online: 06 August 2020

\section{References}

1. Lockwood AH, Salvi RJ, Burkard RF. Tinnitus. N Engl J Med. 2002;347:904-10.

2. Tambs K, Hoffman HJ, Engdahl B, Borchgrevink HM. Hearing loss associated with ear infections in Nord-Trondelag, Norway. Ear Hear. 2004;25:388-96.
3. Yang $H$, Cai $Y$, Guo $H$, Xiong $H$, Sun $Y$, Huang $X$, Zheng Y. Prevalence and factors associated with tinnitus: data from adult residents in Guangdong province, south of China. Int J Audiol. 2018;57:1-8.

4. Bhatt JM, Bhattacharyya N, Lin HW. Relationships between tinnitus and the prevalence of anxiety and depression. Laryngoscope. 2017;127:466-9.

5. Peter N, Kleinjung T, Horat L, Schmidt-Weitmann S, Meyer M, Buchi S, Weidt S. Validation of PRISM (pictorial representation of illness and self measure) as a novel visual assessment tool for the burden of suffering in tinnitus patients. Health Qual Life Outcomes. 2016;14:47.

6. Newman CW, Jacobson GP, Spitzer JB. Development of the tinnitus handicap inventory. Arch Otolaryngol Head Neck Surg. 1996;122:143-8.

7. Kuk FK, Tyler RS, Russell D, Jordan H. The psychometric properties of a tinnitus handicap questionnaire. Ear Hear. 1990;11:434-45.

8. Tyler RS, Gogel SA, Gehringer AK. Tinnitus activities treatment. Prog Brain Res. 2007:166:425-34.

9. Wilson PH, Henry J, Bowen M, Haralambous G. Tinnitus reaction questionnaire: psychometric properties of a measure of distress associated with tinnitus. J Speech Hear Res. 1991;34:197-201.

10. Goebel G, Hiller W. The tinnitus questionnaire. A standard instrument for grading the degree of tinnitus. Results of a multicenter study with the tinnitus questionnaire. HNO. 1994:42:166-72.

11. Meikle MB, Henry JA, Griest SE, Stewart BJ, Abrams HB, McArdle R, Myers PJ, Newman CW, Sandridge S, Turk DC. The tinnitus functional index: development of a new clinical measure for chronic, intrusive tinnitus. Ear Hear. 2012;33:153-76.

12. Terwee $C B$, Bot SD, de Boer MR, van der Windt DA, Knol DL, Dekker J, Bouter LM, de Vet HC. Quality criteria were proposed for measurement properties of health status questionnaires. J Clin Epidemiol. 2007;60:34-42.

13. Shi QL, Bu XK, Wang JG, Lu L, Xu X, Liu C. Translation and application of tinnitus handicap inventory in Chinese version. Acta Universitatis Medicinalis Nanjing. 2007:5:4

14. Meng Z, Zheng Y, Liu S, Wang K, Kong X, Tao Y, Xu K, Liu G. Reliability and validity of the chinese (mandarin) tinnitus handicap inventory. Clin Exp Otorhinolaryngol. 2012;5:10-6.

15. Henry JA, Griest S, Thielman E, McMillan G, Kaelin C, Carlson KF. Tinnitus functional index: development, validation, outcomes research, and clinical application. Hear Res. 2016:334:58-64.

16. Rabau S, Wouters K, Van de Heyning P. Validation and translation of the Dutch tinnitus functional index. B-ENT. 2014;10:251-8.

17. Fackrell K, Hall DA, Barry JG, Hoare DJ. Psychometric properties of the tinnitus functional index (TFI): assessment in a UK research volunteer population. Hear Res. 2016;335:220-35.

18. Buldur B. Angel or devil? Dentists and dental students conceptions of pediatric dental patients through metaphor analysis. J Clin Pediatr Dent. 2018;42:119-24

19. Diener E, Emmons RA, Larsen RJ, Griffin S. The satisfaction with life scale. J Pers Assess. 1985;49:71-5.

20. Beck AT, Epstein N, Brown G, Steer RA. An inventory for measuring clinical anxiety: psychometric properties. J Consult Clin Psychol. 1988;56:893-7.

21. Sterne JA, White IR, Carlin JB, Spratt M, Royston P, Kenward MG, Wood AM, Carpenter JR. Multiple imputation for missing data in epidemiological and clinical research: potential and pitfalls. BMJ. 2009:338:b2393.

22. Jolliffe IT. Principal component analysis. New York: Springer-Verlag; 1986.

23. Peter $\mathrm{N}$, Kleinjung $\mathrm{T}$, Jeker $\mathrm{R}$, Meyer $\mathrm{M}$, Klaghofer $\mathrm{R}$, Weidt $\mathrm{S}$. Tinnitus functional index: validation of the German version for Switzerland. Health Qual Life Outcomes. 2017:15:94

24. Wrzosek M, Szymiec E, Klemens W, Kotylo P, Schlee W, Modrzynska M, LangMalecka A, Preis A, Bulla J. Polish translation and validation of the tinnitus handicap inventory and the tinnitus functional index. Front Psychol. 2016;7:1871.

25. Gignac GEK. A: evaluating dimensional distinctness with correlated-factor models: limitations and suggestions. Intelligence. 2017;62:138-47.

26. Passi S, Ralli G, Capparelli E, Mammone A, Scacciatelli D, Cianfrone G. The THI questionnaire: psychometric data for reliability and validity of the Italian version. Int Tinnitus J. 2008;14:26-33.

27. Zacharia T, Naik PV, Sada S, Kuniyil JG, Dwarakanath VM. Development and standardization of tinnitus handicap inventory in Kannada. Int Tinnitus J. 2012:17:117-23.

28. Hoff M, Kahari K. A Swedish cross-cultural adaptation and validation of the tinnitus functional index. Int J Audiol. 2017:56:277-85.

29. Anthoine E, Moret L, Regnault A, Sebille V, Hardouin JB. Sample size used to validate a scale: a review of publications on newly-developed patient reported outcomes measures. Health Qual Life Outcomes. 2014;12:176. 
30. Fung SF, Fung ALC. Development and evaluation of the psychometric properties of a brief parenting scale (PS-7) for the parents of adolescents. PLoS One. 2020;15:e0228287.

31. Fung SF, Kong CYW, Huang Q. Evaluating the dimensionality and psychometric properties of the brief self-control scale amongst chinese university students. Front Psychol. 2019;10:2903.

\section{Publisher's Note}

Springer Nature remains neutral with regard to jurisdictional claims in published maps and institutional affiliations.

Ready to submit your research? Choose BMC and benefit from:

- fast, convenient online submission

- thorough peer review by experienced researchers in your field

- rapid publication on acceptance

- support for research data, including large and complex data types

- gold Open Access which fosters wider collaboration and increased citations

- maximum visibility for your research: over $100 \mathrm{M}$ website views per year

At BMC, research is always in progress.

Learn more biomedcentral.com/submissions 